\title{
Supported Employment: emerging issues and developments
}

\author{
Garth Bennie*
}

Supported Employment is based on the idea that all people with disabilities have potential for immediate inclusion in real work settings with their non-disabled peers. This paper describes the context in which Supported Employment was conceptualized, articulates its defining characteristics and examines the emerging issues with respect to its current status and future application in New Zealand.

\section{Introduction}

Recent years have seen a move towards a greater range of opportunities aimed at including people with severe disabilities in real work settings and alongside their nondisabled peers. Supported Employment is a term often used to embrace many of these new initiatives. It is a concept which profoundly challenges traditional approaches to vocational rehabilitation by assuming that all people with disabilities have potential for immediate inclusion in regular community employment settings. As a result, Supported Employment insists that the primary issue is not whether a person is ready for employment, but what support arrangements the person will need to enter employment now and how these will be provided. In practice, it challenges the assumption that time limited rehabilitation will lead to long term employment by acknowledging that some people with disabilities will need permanently available support services in order to experience an ordinary working life.

This article describes the context in which Supported Employment was conceptualized, articulates its defining characteristics, and examines some emerging issues with respect to its current status, and future development in New Zealand as a model which promotes the employment of people with disabilities.

The emergence of Supported Employment has been the result of 3 main factors. Firstly, an ecological-behavioural approach to systematic training which demonstrated that even people with very severe disabilities had potential for integrated employment. Secondly, the non performance of sheltered workshops in preparing, "adjusting" or getting people ready for employment. And thirdly, the systematic exclusion from vocational rehabilitation services of those people "evaluated" as not having potential for open employment. In addition, Supported Employment is part of a broader movement aimed at the full inclusion of people with disabilities in the social, educational, economic and political fabric of our communities. This movement had its genesis in the civil rights campaigns of the 1960 s and in the subsequent adoption of philosophies like Normalization in the 1970 s.

As a result, Supported Employment has until recently been a concept largely confined to people with intellectual disabilities. This group, which makes up a high proportion of sheltered workshop participants, significantly benefit from systematic training approaches because of their learning disability, and tend to have the greatest

* Department of Social Policy and Social Work, Massey University. An earlier version of this article was presented as a paper at the National Rehabilitation Conference, May 1991. 
chance of being excluded from vocational rehabilitation services other than sheltered workshops. However, there is growing evidence and demonstration of the successful application of Supported Employment for other groups - people with physical disabilities, sensory impairments, head injury, mental disability, autism and people with multiple disabilities (Wehman and Kregel, 1989).

This raises questions about the validity of current approaches and the possibility that Supported Employment concepts have potential for the reform of not only sheltered workshops, but of vocational rehabilitation in general.

\section{Principles of Supported Employment}

The concept of Supported Employment is rooted in 7 fundamental principles which express philosophical, as well as practical, departures from traditional approaches to vocational rehabilitation (adapted from Powell et al., 1988).

\section{Integration}

Supported Employment is committed to including people with disabilities in regular work settings alongside their non-disabled peers. It insists upon social as well as physical integration so that relationships with co-workers are meaningful, valued and reciprocal, and include non work activities such as social clubs. In this context, the sheltered workshop is viewed as obsolete and a model for which alternatives must be developed.

\section{Placement first}

Supported Employment focuses on the delivery of services and support in the context of an actual job. It is characterized by a process which seeks to discover a person's aspirations, strengths, preferences and support needs (as opposed to deficits and weaknesses), match these to the requirements of a particular job, and to provide whatever support is necessary to maintain that person in the job. People do not have to be job ready. This is in stark contrast to traditional approaches to vocational rehabilitation which insist on extensive periods of work adjustment and readiness training. Unfortunately, for so many people, this is a "training treadmill"; endless preparation from which a job never materializes. Supported Employment represents a reversal of the vocational rehabilitation process from one of assess-train-place to place-train-support. Such a reversal represents a conceptual leap which few traditional practitioners are able to easily make.

\section{Universal acceptance}

Supported Employment services cannot be denied on the basis of severity of disability or complexity of need. Eligibility to enter the workforce is determined by the aspirations of the person, not the opinion of the professional. Current vocational rehabilitation services, on the other hand, seem quite obsessed with "sorting" and "selecting" people to determine potential, readiness and eligibility for services. This is represented by an obsessive commitment to testing and evaluation practices which have been repeatedly shown to have little validity in determining employment potential. Such a process is "anti-habilitative".

Supported Employment demands a new response from vocational rehabilitation practitioners. Instead of thwarting a person's aspirations to join the workforce, by 
determining and questioning "readiness", efforts are directed at what support is necessary to make employment a reality now. This forces practitioners to focus on the readiness of employers, co-workers and, ultimately, the labour market itself, rather than upon ameliorating individual deficits through endless "prerequisite" training.

\section{Wages and benefits}

Supported Employment is work for pay. People must be paid for the work they do and receive associated benefits, annual leave, sick leave, bonuses, training opportunities, etc. Although the goal is always minimum pay or better, Supported Employment does accept the initial possibility of sub-minimum wages, but only under the auspices of appropriate permits that are subject to regular and independent review. If minimum pay were a universal criteria for workforce entry then those with more complex needs would be excluded from the possibilities of integrated work, and find themselves restricted to permanent "readiness training" or segregated work (without pay). Supported Employment also acknowledges the important social dimensions work has in enhancing self esteem, expanding social networks, structuring lifestyle and contributing generally to our mental health. Employer expectations with regard to productivity are met through the combined efforts of the person, people such as job coaches and the individual's ongoing support services.

There are a variety of payment mechanisms which could be utilized that are respectful and still reflect the person's contribution (Hagner, Nisbet et al., 1987). Nevertheless, the current situation with regard to "underrate" permits in New Zealand is far from satisfactory. Their administration and review is ad hoc and criteria fail to take account of the person's total contribution to the workplace. Restricting permits to 3 levels of pay ( 25 percent, 50 percent and 75 percent) would also go some way to reducing abuses at either end of the spectrum.

\section{Flexible support}

On the job support may involve the coordination and/or delivery of a wide range of services, the type of support being individually determined. It could include intensive training, workplace adaptation, the services of a rehabilitation engineer, advocacy, the application of EEO procedures, the securing of wage subsidies, advice to co-workers etc., with the possible combinations being endless. In addition to providing services, an agency may also broker, mobilize and create support resources. The term "job coach" is often used to describe the person who provides on the job support and may coordinate the process or be one of several personnel being coordinated by an agency.

\section{Lifelong support}

Supported Employment accepts the possibility that some people may require permanently available agency provided support services, even after all reasonable attempts have been made to shift these to naturally occurring resources such as supervisors and coworkers. The provision of support which is not time limited is central to Supported Employment, acknowledges the inevitability of changing circumstances, and demands a considerable shift in resources from pre-placement training and assessment to on-the-job training and ongoing support. Current approaches assume the person is job ready at the point of placement. However, the high incidence of unemployment and repeated job failure for people with disabilities belies this and, again, calls into question not only the validity of assessment procedures and work adjustment activity, but the rehabilitation 
process itself, especially in the context of its tacit acceptance of the current labour market and its "ableist" tendencies.

Taken out of its human service context, the idea of Supported Employment is something which can be found operating in most people's working lives: significant others, within and outside the working environment, playing a number of roles in providing support and meaning to our employment - usually informally and incidentally, but sometimes on a more formal basis, for example, referral to an employment service as a result of redundancy. For people with disabilities, informal and incidental support may not be adequate to either gain workforce entry or maintain employment. Supported Employment offers a means through which support can be systematically identified, planned, mobilized, coordinated and monitored to ensure that employment firstly becomes a reality and secondly does not fall victim to the barriers and prejudices which exclude peop?e with disabilities from the workplace.

\section{Choices}

Supported Employment should assist the person to make truly informed decisions about their working lives as opposed to having these determined or circumscribed by tests, evaluations or professional opinion. A number of short term work experience opportunities may be helpful in this regard and could provide agencies a means of becoming aware of a person's support needs, but should not be used to determine readiness or eligibility, or left indefinitely to become a permanent and unmonitored situation which passes for a job. Supported Employment requires a well developed matching procedure in order to ensure that the support resources available have a high probability of overcoming any discrepancies between the person's current abilities and job requirements.

Together, these principles imply that vocational rehabilitation practitioners develop quite different relationships with families, employers and co-workers and especially with people who have disabilities. Employers, in particular, are invited to participate in a process that not only challenges their assumptions about productivity and work readiness of people labelled disabled, but also long held beliefs about their roles in relation to rehabilitation and employment support agencies. It also asks rehabilitation practitioners to develop a far more critical perspective on the contemporary labour market.

\section{Models of Supported Employment}

Historically, Supported Employment has been delivered through several models:

\section{Individual placement strategies}

These typically involve the provision of a job coach who provides on-site advocacy, training and who often coordinates the range of support services required. The job coach aims to fade from the job site by transferring ongoing support to co-workers and supervisors. However, regular site visits can continue indefinitely. There are also some promising approaches that keep on-site agency involvement to a minimum (Nisbet and Hagner, 1988). For example, Mentors (where a particular co-worker acts as liaison between employer and agency, as a reference point for other co-workers and for which the agency may pay a fee); Advisers (where a particular co-worker is paid for specific support duties in addition to the time spent with the person); Job sharing (where the agency may recruit 2 people for a position, or where 1 person's wages are paid jointly by the agency, for support services, and by the company, for production); Attendants (who provide 
assistance with personal care routines and are hired by the person); and clustering strategies where 3 or 4 people are placed in close proximity, but with different employers (e.g. in a shopping centre) and are supported by a mobile job coach.

It is through individual placement strategies that the greatest levels of integration and chances for wages at or above the legal minimum are achieved and these are emerging clearly as the preferred model of practice in Supported Employment. There is an ongoing challenge though, to develop procedures which minimize dependency on direct agency supports and maximize employer and co-worker commitment and involvement.

\section{Enclaves (or workstations)}

These involve a contract between an agency and employer where a small group of people with disabilities and a full time agency supervisor undertake designated work on the employer's premises. The contract is with the agency, not the individuals, so payment is by the agency not the company. Enclaves afford people a level of integration and wages not usually possible in sheltered workshops. However, the extent of both is often hampered by the perception that the participants are still clients of a social service agency rather than employees of a company. While the aim is to either use the enclave as a training opportunity or for the individuals to gain regular jobs in the company, it is more often the case that it becomes a fairly institutionalized structure where levels of integration, wages and other job opportunities rarely move beyond a certain point. Dictionary definitions of enclaves serve to remind us of their limitations: "an area reserved for a minority group" (Heinemann New Zealand) and "an outpost surrounded by enemy territory" (Websters).

\section{Mobile work crews}

Essentially these are mobile enclaves involving several smaller contracts with a number of employers. The agency usually supplies the transport and equipment. While wages and integration are sometimes greater than in sheltered workshops, this is not always the case due to the nature of the work (lawnmowing, cleaning), the time at which it is undertaken, and the high overhead costs. The business acumen required to run one or more mobile crews is often not available in agencies. Because of their tendency to maintain the isolation of people, they have sometimes been referred to as "mobile segregation" (Moura and Dileo, 1989).

\section{Small business enterprises}

These attempt to blend the role of employment support and commercial operation involving workers with and without disabilities in small scale businesses. In practice, it remains essential to separate funding for support services so that this is not used to offset costs of commercial operation. These costs need to be financed in the same way as for any small business.

The small business requires a level of management expertise which is rarely found because habilitation and commercial interests are difficult to balance. Subsequently, many small businesses simply resemble small sheltered workshops and find it difficult to avoid perpetuating negative stereotypes of people with disabilities. There are, however, some rare exceptions, usually involving cooperative management and/or ownership arrangements where the status of the business and its employees is enhanced. 
In the final analysis though, habilitation agencies will have to move away from being the major "employers" of people with disabilities if integration is going to become the norm.

\section{Emerging issues: a brief overview}

What follows is something of a potpourri of issues. These are offered to highlight concerns, to promote dialogue about Supported Employment and to extend our thinking about the organization and practice of vocational rehabilitation as a means of including people with disabilities in the workforce.

- There is considerable debate emerging about whether enclaves, mobile crews and small businesses are in fact Supported Employment. Although regarded as such in legislation in both Australia and the US, it is the individual placement model which best represents the concept, and is clearly the preferred model in practice. However, we should not ignore the part that small group strategies can play. Although not offering ideal levels of integration and wages, they are often a considerable improvement on work options offered in sheltered workshops. They can also reduce anxiety and fears about the prospect of integration. And why should people in sheltered workshops and others who are disenfranchised by the vocational rehabilitation system have to wait for the perfect employment service?

On the other hand, it is important to view these small group options as short term responses to the segregated present, and not as ends in themselves. Safeguards need to be in place to ensure that enclaves, mobile crews and small businesses do not outlive their utility and restrict the choices of people with disabilities as better employment options become more widely available.

- Supported Employment is often regarded as a complete alternative to sheltered workshops. This is a far too simplistic view and ignores the multiple role that sheltered workshops play, whether by design or default, in the lives of those who attend them. As well as a place of work (albeit segregated and without pay), they can also be the only currently available opportunities for socialization, education and recreation. Supported Employment should only be part of a broad based strategy to convert sheltered workshops into habilitation support services that promote integration in all aspects of community living and including integrated leisure, adult education and employment.

This highlights the need for rehabilitation to develop a more holistic or "lifestyle" approach which views employment as just one dimension (although often a crucial one) of an integrated and meaningful life in the community.

The process of integration should also lead to an expansion of people's personal networks not, as it is prone to, asking people with disabilities to exchange one set of relationships with another as they move from segregated to integrated participation in the community. The power of mutual solidarity gained from being a member of an oppressed group should not be dissipated in our rush to "normalize" services.

- There is a tendency for agencies and programmes to adopt the term Supported Employment, but without making any philosophical or practical changes to services or making any commitment to its underlying principles. Funding agencies, in particular, will therefore have to have clearly articulated policy and effective quality assurance mechanisms. Both are conspicuous by their absence at the present time.

- Both vocational rehabilitation and Supported Employment tend to immerse themselves in unnecessary technical sophistication rather than making serious attempts to 
overhaul an essentially dysfunctional service system - one that views disability as a question of individual pathology rather than as a social construction that serves to oppress and marginalize people labelled as such. The results are over-professionalized services, fragmented intervention processes, and hierarchical agency structures (Bennie, 1991). This can manifest itself in several ways, for example:

- Supported Employment services offering a continuum of services whereby one must start in a small business, "graduate" to an enclave or mobile crew and, when one is "ready", become eligible for individualized placement. Clients become caught in the continuum with very few graduating - reflecting a retreat to the endless readiness and work adjustment training of traditional workshops and vocational rehabilitation (Taylor, 1988).

- Services (including those that promote integration) tend to create multiple professional roles to undertake the various pre and post placement tasks. For example, different staff, or even different agencies, for intake and assessment, job search and development, job coaching and follow up or ongoing support. Services inevitably become unnecessarily complex where clients, their families, employers and co-workers are bound to get confused, frustrated and simply "lost". It is time we had generically trained personnel who can stay with the person throughout the process and minimize the client's having to be exposed to a multitude of professionals. At present it seems that everyone wants to provide information, assess, coordinate and broker, but is there going to be anyone left to actually support people with disabilities in jobs? Subsequently, there is a propensity in vocational rehabilitation to create careers for professionals, rather than jobs for people with disabilities.

- The relationship between Supported Employment and vocational rehabilitation needs to be sorted out. Is Supported Employment a new option within existing vocational rehabilitation services, or does it represent the possibility of widespread reform of the whole system? Certainly it calls into question the validity of many conventional practices around vocational evaluation and work adjustment training, and although it was originally intended for people with intellectual disabilities, it impresses as a concept that, with further development, has relevance for anyone with a disability who wants to join or rejoin the paid workforce. Although some people may wish a long period of work adjustment and training because a particular entry point in the workforce has been identified, one wonders how many people with disabilities would be satisfied with such an undertaking if they were aware that there are service options committed to immediate workforce entry, accepts them as they are, and are concerned not with how ready they are, but with what kind of support they require. In this context, such tasks as discovering a person's IQ and other testing and sorting activities represent gross infringements of civil rights rather than valid habilitation procedures.

Some have suggested that the role of vocational rehabilitation services is to identify quality Supported Employment programmes with a view to contracting out job coaching and ongoing support functions (Wehman and Moon, 1988). There are difficulties with this; firstly in the ability of vocational rehabilitation services to recognize quality Supported Employment; secondly, because it fragments the habilitation process at its most vulnerable point (at or soon after placement); and thirdly, because it is a whole new approach, not just a procedure for supporting someone in a job on an ongoing basis. Supported Employment is not a new option within vocational rehabilitation, but is part of a reform movement which challenges the very assumptions and values upon which conventional vocational rehabilitation is based.

- The concept of Supported Employment must begin at school. The successful transition from school to work remains elusive for the majority of students with disabilities and they tend to be excluded from transition programmes that do exist. Far too many have their post school future prescribed very early on, through restrictive 
practices such as special classes and special schools. An inevitable consequence of segregated schooling is a segregated working life. Where serious attempts at transition to integrated work or further education are made, this is often hampered by the inability of involved agencies to define their various roles and responsibilities or to adequately coordinate services.

Furthermore, continuing education and training provision in ACCESS programmes and polytechnics tends to replicate the segregation practised in the school system rather than supporting the inclusion of people with disabilities in generic courses.

- The separateness of vocational rehabilitation, including Supported Employment, from the generic provision of employment support, education and training services, perpetuates the segregation of people with disabilities from the regular workforce. It is ironic that the promotion of integration is so often taking place within quite segregated and disparate service structures. The concept and practice of integration needs to encompass strategies which bring about change and the provision of opportunity, support and services within generic community facilities - the New Zealand Employment Service, ACCESS, polytechnics etc. Vocational rehabilitation should support generic provision, not supplant this with unnecessarily specialized and usually segregated programmes.

Service users and their advocates should therefore be able to directly interact with generic services without vocational rehabilitation playing gatekeeper, but instead, supporting the rights of consumers to use the same services as everyone else, ensuring that they control the intervention process, and also determine what professionals and agencies get involved, and in what capacity. The absence of such strategies will mean that generic services and the national education and employment policies which underpin their operation, will continue to develop without regard to the inclusion of people with disabilities.

- In New Zealand, there is a yawning gap in the availability of nationally coherent preservice and in-service training opportunities which encourage a critical appraisal of current services, practices and policies, and which promote innovation that is on the cutting edge of development. Personnel require a more generic based training that allows them to integrate knowledge and practice from a variety of disciplines and assists them to conceptualize disability, not in terms of individual pathology, but in terms of the social oppression of people with impairments. The absence of personnel well versed in new philosophies and practices in adequate numbers may yet prove to be the major obstacle to the reform of vocational rehabilitation and the employment of people with disabilities in significant numbers.

- There is an acute need to develop models which integrate vocational rehabilitation and Supported Employment into a coherent system which accepts all people with disabilities as potential members of the workforce. It is not time for this country to simply adopt American or Australian models where each are regarded as different service types and have their own funding and service structures. This perpetuates the sorting and selecting of people according to whether they are (a) likely to earn the minimum wage or (b) require ongoing support. The result is 2 systems continually seeking to exclude people on the basis of their "level" of disability and both supporting a labour market which, by its very nature, is rejecting of people with disabilities.

- The initiation of a number of projects aimed at applying new models in practice, longitudinal studies of new approaches, and a uniform framework for cost/benefit and comparative analysis of all vocational rehabilitation programmes, no matter what their vintage, are but a few of the urgent requirements in terms of research and policy 
development. These are essential activities if any new legislation is going to promote the changes that people with disabilities actually want.

- New Zealand's recently deregulated labour market poses new challenges for people with disabilities and increases their vulnerability along with other groups who tend to be marginalized in terms of employment. This is not to suggest that the situation was any better for people with disabilities before the Employment Contracts Act - Unions have always been slow to acknowledge the rights of people with disabilities and to promote their employment. Unions have not traditionally been a source of advocacy in this regard. For example, the union movement does not appear to recognize the exploitation that passes for rehabilitation in many of this country's sheltered workshops. The time may be right for the emergence of a "Workers Alliance" of, and for, people with disabilities. Such a group could have a number of roles:

- The promotion of integrated employment.

- An advocacy role in the negotiation of individual contracts and in the negotiation of collective agreements to ensure that the needs of people with disabilities are accounted for (especially with regard to under rate permits and the legitimation of ongoing support strategies involving job coaches and co-workers).

- Monitoring the philosophies and practices of vocational rehabilitation agencies.

- Monitoring the application of EEO procedures to ensure the spirit of the concept is upheld rather than employers simply following the "letter of the law".

- "Outcomes" - the new buzz word from the New Right. Much is being made of determining the success of vocational rehabilitation in terms of very simplistic and misleading outcomes such as numbers placed in jobs and numbers placed in training. Surely it is more meaningful to characterize outcomes in terms of what happens to people because of the job, or because of the training course. In the context of new concepts such as Supported Employment, this leads us to ask much more probing questions in terms of outcomes. For example:

- How long are people retaining their employment?

- How long are people in training - are they on the "treadmill"?

- What kind of jobs are people in, and what is happening in terms of advancement and promotion?

- What is the level of renumeration and how does it compare with co-workers'?

- As a result of employment and/or training, has the person increased their economic self-sufficiency? Is he or she acquiring new skills and competencies? Has there been an increase in self esteem? Has the person's network of relationships expanded? Does the person with the disability consider that their quality of life has improved as a result of employment and/or training?

\section{Some concluding thoughts}

As an oppressed group, people with disabilities find themselves in an ironic position with regard to employment. Whilst the present structural dynamics and relationships which determine the context in which people with disabilities work can often be regarded as essentially exploitive and alienating on the one hand, the political and economic power required to change this structural inequality, on the other, will usually necessitate access to, and participation in, the labour market as a prerequisite.

In this context, current models of vocational rehabilitation, including Supported Employment, are not helpful with regard to the structural transformation required in the labour market, and within employment settings for people with disabilities to be unconditionally accepted. If educational mainstreaming is about changing mainstream schools and classrooms, then Supported Employment should ultimately be about 
changing the labour market. Current approaches essentially promote the assimilation of people with disabilities into employment settings without challenging the structural inequalities which alienate them from and within the labour market in the first place (along with other marginalized groups). People are consequently asked to "fit in" and accept these structural inequalities as inevitable, and the focus of rehabilitation tends to be on this "adjustment" process. As a result, when employment does occur, it is nearly always on the margins of the labour market.

Supported Employment signals the possibility of redefining the process of vocational rehabilitation. Its concern with the dynamics of the workplace in the widest sense (rather than just with the individual) offers up potential for the development of strategies which challenge employment settings to make fundamental rather than cosmetic changes, so as to include people with disabilities. However, Supported Employment has yet to fully escape the traditions of conventional vocational rehabilitation. As a concept it requires considerable development in order to provide an adequate framework both for the analysis of structural inequality in the workplace (in terms of disability), and for the identification of practices aimed at the transformation of structures and processes that dictate the nature of employment settings and access to them. Currently, these persist in not only keeping people with disabilities out of the workforce, but often in situations without adequate or unconditional access to those services and programmes which are supposed to promote their employment in the first place.

\section{References}

Bennie, G. (1991) Employment support and continuing education for people with disabilities. Auckland, School of Special Education, Auckland College of Education (Study Guide).

Hagner, D., Nisbet, J., Callahan, M. and Moseley, C. (1987) Payment mechanisms for community employment: realities and recommendations. Journal of the Association for People with Severe Handicaps 12(1):45-52.

Moura, J. and Dileo, D. (1989) Mobile crews: some concerns about mobile segregation. New Hampshire, New Hampshire University, Institute on Disability.

Nisbet, J. and Hagner, D. (1988) Natural supports in the workplace: a re-examination of Supported Employment. Journal of the Association for People with Severe Handicaps 13(4):260-267.

Powell, T. et al. (1988) Supported Employment in Connecticut: developing integrated employment opportunities for persons with disabilities. Glastonbury, Corporation for Supported Employment.

Taylor, S.J. (1988) Caught in the continuum: a critical analysis of the principle of least restrictive environment. Journal of the Association for People with Severe Handicaps 13(1):41-53

Wehman, P. and Kregel, J. (eds.) (1989) Supported Employment for people with disabilities: focus on excellence. New York, Sciences Press.

Wehman, P. and Moon, M.S. (1988) Supported Employment and vocational rehabilitation. Baltimore, Paul Brookes. 